\title{
Experimental investigations into sacrificial support for containment of rockburst damage
}

\author{
A Mudau University of the Witwatersrand, South Africa \\ TR Stacey University of the Witwatersrand, South Africa \\ RA Govender University of Cape Town, South Africa
}

\begin{abstract}
Recently, a support method termed 'sacrificial support' was proposed as a potential additional method to prevent rockburst damage, based on observations made after rockburst events in a mine. The philosophy behind a sacrificial support system is that: under dynamic loading conditions support, in the form of a liner, must fail leaving behind, undamaged, what was once supported rock mass.

In this paper, spalling tests based on Split Hopkinson pressure bar technique were conducted to study some aspects of dynamic rock fracturing in tension at high strain rates and the role a sacrificial layer plays in combating dynamic rock failure. To achieve this, a single Hopkinson pressure bar, with a long cylindrical intact rock specimen attached at the bar free end, was impacted by a striker on the opposite free end of the bar in order to generate a dynamic stress pulse responsible for spall failure upon reflection from the specimen free end. Different liners and/or liner combinations were then introduced at the specimen free end as support. Such a simple, yet robust experimental set-up, allowed the potential benefits and failure mechanisms associated with sacrificial support under dynamic loading to be demonstrated. Analysis of experimental results revealed that varying liner thickness and mechanical impedance between rock and support liner plays a significant role to help limit rockburst damage.
\end{abstract}

Keywords: rockburst, sacrificial support, Split Hopkinson pressure bar

\section{Introduction}

The growing need for development of underground structures such as tunnels, nuclear repositories, caverns, bunkers, and advancement of mine workings etc. has required engineers around the world to come up with robust designs to ensure the stability of these structures, during their service life and even afterwards. In all cases, these structures are driven in rock masses exhibiting varying degrees of competence, subjected to quasi-static or dynamic loading.

Rockbursts continue to be major contributors to mine accidents and to violent damage of mine excavations, particularly at great depth. The problem of rockbursts has also escalated in civil engineering tunnels driven at depth due to the increase in in situ stress fields at such depths. Attempts have been made in the past to mitigate the drastic impacts caused by rockburst damage, with rock support remaining the ultimate method for providing stability in rockbursting environments. However, records show that on many occasions conventional support elements, such as rockbolts, wire mesh, shotcrete and lacing, fail to withstand severe rockburst damage.

Recently, a support method termed 'sacrificial support' was proposed as a potential additional method to prevent rockburst damage, based on observations made after rockburst events in a mine (Stacey \& Rojas 2013). The philosophy behind a sacrificial support is that: under dynamic loading conditions support, in the form of a liner, must fail leaving behind, undamaged, what was once supported rock mass. This type of support was termed a sacrificial support because it saved the rock from damage, with failure only experienced by the support itself, during a rockburst. This support concept is based on a wave trap mechanism previously suggested by Stacey (1991). In this concept, for example for a concrete lined tunnel, 
the compressive seismic wave passes through the rock/concrete contact and then reflects at the concrete/air interface, since air cannot sustain the passage of compressive waves. On reflection, the compressive wave is converted into a tensile wave, which then travels back down to the concrete/rock contact. Since this contact has no tensile strength, the tensile wave is trapped in the concrete layer and the concrete is ejected, leaving the rock surface undamaged.

The study by Stacey and Rojas (2013) left some important questions unanswered pertinent to sacrificial support behaviour. The research described in this paper aims to provide answers to the following questions pertaining to different support layers of the materials investigated:

- Is a minimum thickness required for the layer (i.e. support layer) to effectively resist dynamic rock failure (i.e. rockburst damage)?

- What are the effects of the different stiffnesses of support layers/liners in the capability to combat the effects of stress waves?

The proposed support concept may sound controversial, but this paper will demonstrate, through simple experimental arrangements, the potential benefits and failure mechanisms associated with sacrificial support under dynamic loading. The sacrificial support concept reported herein is applicable in situations where the source (i.e. seismic event) of the rockburst is located remote from where rockburst damage is likely to occur.

\section{Experimental methods}

It is difficult, if not impossible, to simulate real rockburst conditions, either in the field or laboratory. Most of the studies conducted in the past on rock support performance, under dynamic loading conditions have been through underground blasting experiments or drop weight tests (for example, Ortlepp \& Stacey 1997; Player et al. 2008). With blasting experiments, it has been noted that gas expansion plays a significant role in causing rock fragmentation, rather than rock failure being only a result of reflection of shock waves from free surface, as would be expected in real rockburst situations. In drop weight tests, there is no interaction between rock mass and tested support system, since testing is done by releasing a suspended mass with certain kinetic energy to directly impact the support system. Both of these test methods should, however, be credited with providing some insights on support performance under dynamic loading conditions, but not on the basis of simulating real rockburst conditions (Stacey 2012).

In light of the difficulties associated with simulating rockburst conditions, it was found essential to search for a simple, yet robust, testing methodology with the capability of studying dynamic rock fracturing in a controlled laboratory environment. The Split Hopkinson pressure bar (SHPB) is one of the most popular and well-established techniques used to test a range of materials at high strain rates.

\subsection{Spall testing with the SPHB}

In order to study spall failure phenomena, a single Hopkinson pressure bar (HPB) may be used instead of the two bar configuration often used for standard SHPB compression tests. Govender et al. (2011) demonstrated the spall damage phenomenon for a long rod specimen directly impacted by a projectile. Specimen failure occurs at a location when the resultant stress between the incident compressive stress wave and the reflected tensile stress wave exceeds the tensile strength of the material. This failure mechanism is common in situations wherein the source of stress waves is distant from where failure is realised, e.g. failure observed in a tunnel remote from the seismic source. High ejection velocities in rockbursts often exhibit spall fragments, and this is a serious issue of concern from a safety point of view.

Shock/stress waves generated from a seismic event in a mining environment are complex to understand and simulate. As a result, a one-dimensional (1D) stress wave propagation approach was adopted for simplicity. Spalling phenomena described herein also assume a 1D theory of stress wave propagation in elastic media. 
Figure 1(a) shows a SHPB set-up for a spalling test of a long cylindrical specimen attached at the right hand end of the HPB, while Figure 1(b) is a modification of the SHPB set-up with a liner attached to the specimen. Both the input bar and specimen are supported by bushings in order to minimise friction, and their movement is restricted to one degree of freedom in the $x$-direction. The bushings are aligned beforehand to ensure that the striker, input bar and specimen are co-linear at the start of the test. Before testing of specimens, the input bar is calibrated for wave speed and stress level.

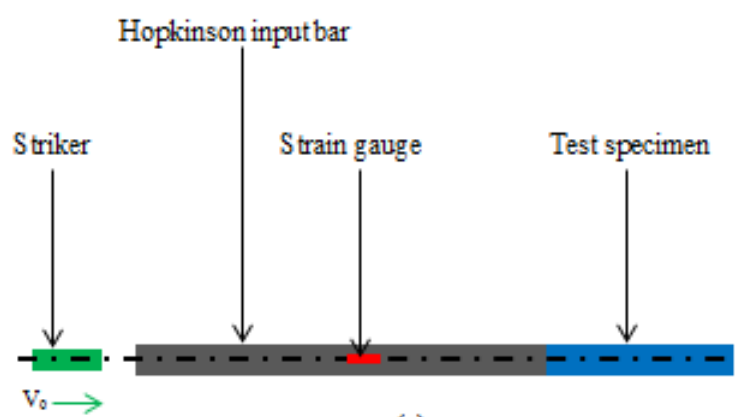

(a)

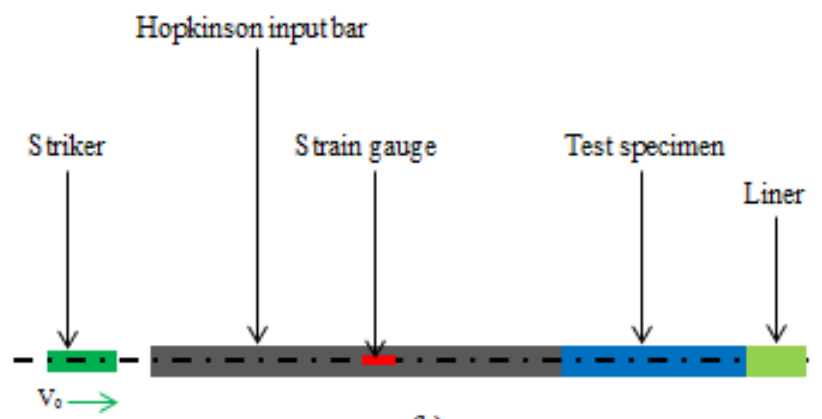

(b)

Figure 1 Schematic representation of spall failure in a long rod loaded by impact (adapted from Govender et al. 2011)

In order to induce a stress wave, a gas gun is used to propel the striker to impact the input bar. The generated transient strain pulse will then propagate down the input/transmitting bar as a longitudinal compressive stress wave, and on arrival at the bar/specimen interface, part of the compressive stress wave will be reflected back as a tensile stress wave due to bar/specimen impedance, whereas the remainder of the compressive stress wave will travel through the specimen and be reflected back at the specimen free end. The transmission of stress waves at the contact between two-layered media is governed by their mechanical impedance ( $Z=\rho C_{0}$, where $\rho$ is the density of material and $C_{0}$ is the wave speed). To achieve satisfactory wave transmission at bar/specimen interface in the SHPB, grease is applied at the contact. A pair of strain gauges, cemented diametrically opposite at the mid-length of the input bar, is used to measure the amplitudes of incident and reflected waves. A calibration factor is then used to convert the recorded output voltage into stress. The dynamic stress pulse can be shifted in time from the centre of the bar to the bar/specimen interface using a time shift based on 1D wave propagation. 1D wave propagation is assumed, which implies the wave does not change shape as it propagates axially. Therefore the stress at any location in the specimen may be inferred by first applying a suitable time shift to the incident and reflected waves measured at the strain gauge, then superimposing these to obtain the resultant stress.

In this study, centreless ground silver steel was used for the input bar. The centreless ground bar ensures that uniformity, in terms of the cross-sectional area and straight neutral axis, is attained throughout the entire bar length (Gama et al. 2004). The input bar used had a nominal diameter of $25 \mathrm{~mm}$ and was $2,000 \mathrm{~mm}$ long. Kyowa ${ }^{\mathrm{TM}}$ strain gauges with a length of $2 \mathrm{~mm}$ were glued at the mid length of the bar. SHPB tests, in general, require a data acquisition system with a high sampling rate (Zhou et al. 2012). The stress wave signal, measured as output voltage at the input bar strain gauge station, was amplified before it could be recorded by a 16 bit data logger at $10 \mathrm{MHz}$. Table 1 below summarises some properties for the silver steel used in this study. 
Table 1 Some properties of silver steel

\begin{tabular}{ll}
\hline Parameter & Value \\
\hline Yield strength & $600 \mathrm{MPa}$ \\
Density & $7,817 \mathrm{~kg} / \mathrm{m}^{3}$ \\
\hline P-wave velocity $\left(C_{0}\right)$ & $5,250 \mathrm{~m} / \mathrm{s}$ \\
\hline
\end{tabular}

A profiled striker was machined from the same material as that of the input bar. A short striker was used as a projectile in order to induce a short pulse duration, which is ideal in the context of a spalling test, wherein a short pulse with short wavelength, less than the specimen length, is a pre-requisite in order to induce spall damage. Since the generated pulse could contain some oscillations, a pulse smoother was used to eliminate the Pochammer-Chree mode high frequency oscillations. Regarding the impact of the input bar with a striker, it was ensured that the bar was always loaded within its elastic limit.

\subsection{Specimen preparation and materials characterisation}

Test specimens of anorthosite, norite and marble were prepared for both quasi-static and dynamic tests. Cylindrical rock specimens were obtained through laboratory core drilling, and all of the specimens were cut to the required lengths. Thorough visual inspection was conducted to make sure all of the test specimens were free of cracks or vein-like structures.

Spall testing requires relatively long cylindrical specimens. The diameter of the specimens is the same as the diameter of the HPB to be used, to facilitate even loading across the specimen face. In this study, an input bar with nominal diameter of about $25 \mathrm{~mm}$ was used, hence all of the spall test specimens were prepared with a similar diameter to the input bar. The range of lengths of tested rock specimens was between 285 and $350 \mathrm{~mm}$.

It is important to determine the quasi-static rock mechanical properties before one conducts spall tests with the SHPB. One of the fundamental pre-requisites of spall testing is that the test specimen must not be loaded beyond its compressive strength. With that in mind, the dynamic stress pulse magnitude in the SHPB can be controlled to fall below the rock material compressive strength by regulating the velocity at which the striker is fired. However, the reflected stress wave from the specimen free end must be sufficient enough to break the specimen in tension.

Accurate data on the mechanical properties of rocks is of paramount importance in the fields of rock mechanics and rock engineering. At least five specimens per rock type were subjected to two quasi-static tests. Table 2 summarises the uniaxial compressive strength data and deformation properties (i.e. Young's modulus and Poisson's ratio) of anorthosite, norite and marble. Data for Brazilian tensile strength tests (BTS) are also included in Table 2 . In addition, an ultrasonic technique was used to measure the p-wave velocity in the tested rock materials, to aid in determining the impedance mismatch of rock relative to the HPB.

Table 2 Mechanical properties of rocks tested

\begin{tabular}{lllllll}
\hline Rock type & UCS (MPa) & BTS (MPa) & $\begin{array}{l}\text { Young's } \\
\text { modulus } \\
(\mathbf{G P a})\end{array}$ & $\begin{array}{l}\text { Poisson's } \\
\text { ratio }\end{array}$ & $\begin{array}{l}\text { Density } \\
\left(\mathbf{g} / \mathbf{c m}^{3}\right)\end{array}$ & $\begin{array}{l}\text { P-wave } \\
\text { velocity } \\
\text { (m/s) }\end{array}$ \\
\hline Anorthosite & 239 & 11 & 93 & 0.30 & 2.78 & 4,463 \\
\hline Norite & 233 & 15 & 95 & 0.27 & 2.64 & 4,640 \\
\hline Marble & 104 & 4 & 78 & 0.32 & 2.88 & 5,200 \\
\hline
\end{tabular}




\section{Experimental observations from Split Hopkinson pressure bar tests}

Different liner materials were tested to evaluate their potential to prevent rock spallation using the experimental set-up previously described. A liner refers to the material attached at the free end of the rock specimen, and it must have a similar diameter to the rock specimen to avoid specimen/liner area mismatch. Before the performance of various liners could be evaluated, rock test specimens were tested without any form of liner to allow the rock the freedom to fail dynamically due to the effect of the reflected tensile stress wave from the free end.

\subsection{Experimental results for tests without liners}

Below are examples of sequences of frames of failed rock specimens without liners captured by the high-speed camera (Figure 2). All specimens were tested at relatively similar loading conditions by controlling the striker impact velocity. All the failed specimens are characterised by multiple fragmentation patterns.

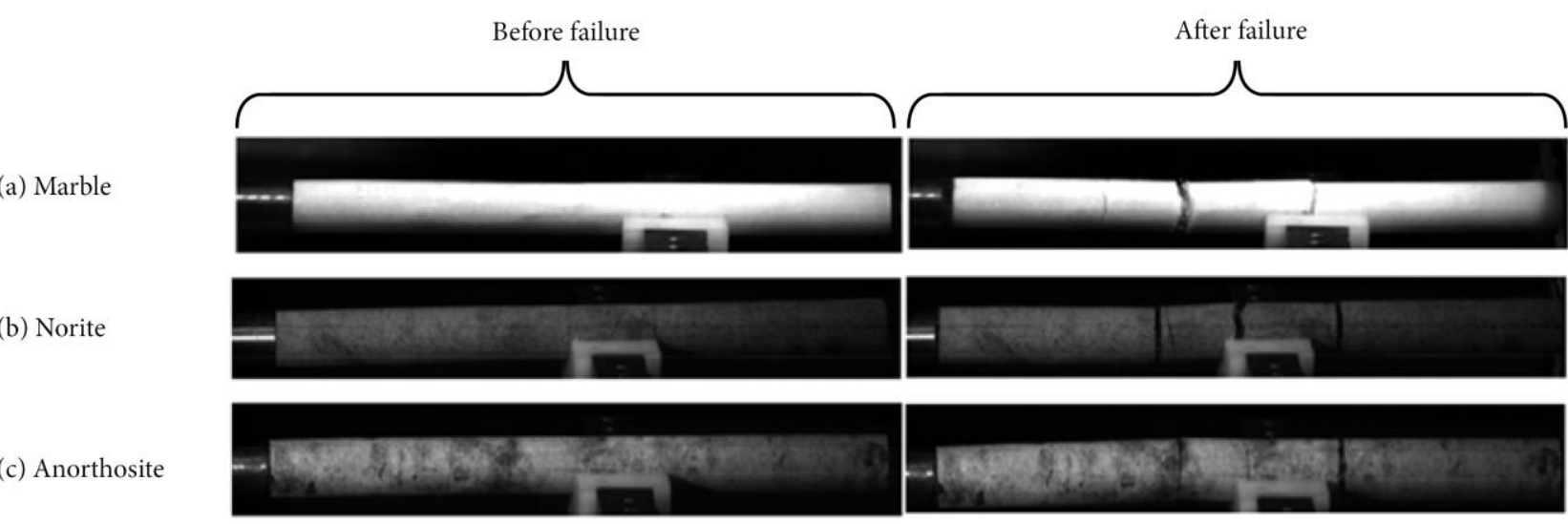

Figure 2 Frames of different rocks tested, before and after spalling damage

\subsection{Experimental results for tests with liners}

Concrete and clay liners were chosen following the behaviour of sacrificial layer in real rockburst event reported by Stacey and Rojas (2013). The concrete had a density of $2,500 \mathrm{~kg} / \mathrm{m}^{3}$ and a $\mathrm{p}$-wave velocity of $3,440 \mathrm{~m} / \mathrm{s}$.

The liners used were considered to be a fair representation of low to high impedance mismatch between rock specimen and support liner. A series of performances of various liner materials under dynamic loading is presented below.

\subsubsection{Tests with $45 \mathrm{~mm}$ thick concrete liner (concrete liner series)}

A weak fine-grained concrete was used in this study, and it was allowed to cure for 14 days. Initially, all the concrete liners were arbitrarily prepared at a nominal thickness of $45 \mathrm{~mm}$ as part of the trial run. Figure 3 shows the behaviour of different rock types supported with concrete liners with this nominal thickness. There is relatively little difference in terms of rock fragmentation patterns, despite the introduction of the liners, compared with the behaviour of rock specimens reported above without liners. 


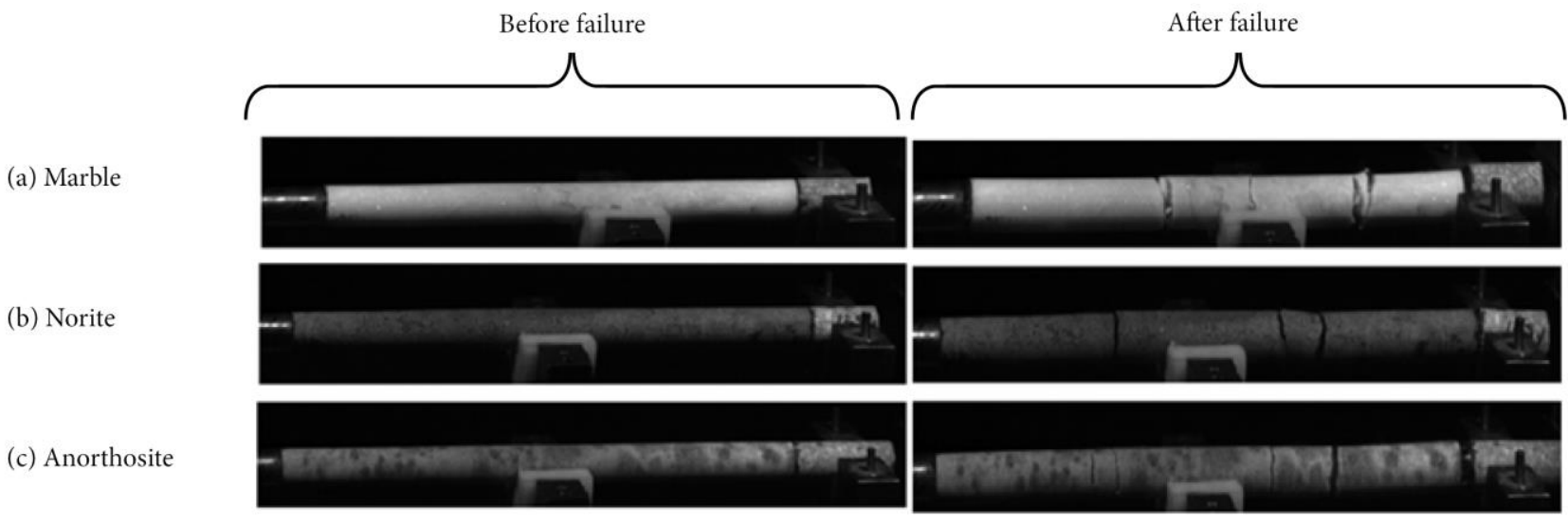

Figure 3 Different rock test specimens supported with $45 \mathrm{~mm}$ concrete liner

\subsubsection{Tests with $10 \mathrm{~mm}$ thick clay liner (clay liner series)}

The clay material of choice used in the study was bentonite. Bentonite and water were thoroughly mixed in a container to produce a slurry-like mix. The minimum thickness for the clay liner was $10 \mathrm{~mm}$ and a plastic tube was used to contain it. It was difficult, if not impossible, to fill the plastic tube containment beyond a thickness of $50 \mathrm{~mm}$ for the parametric study, due to difficulties associated with handling wet clay.

From the photographs in Figure 4, marble specimens spalled at one location, resulting in two fragment pieces. This is an interesting result on the performance of clay in trying to alter the strength of dynamic stress wave to rock damage. On the other hand, anorthosite and norite are characterised by a two-spall fragmentation pattern.

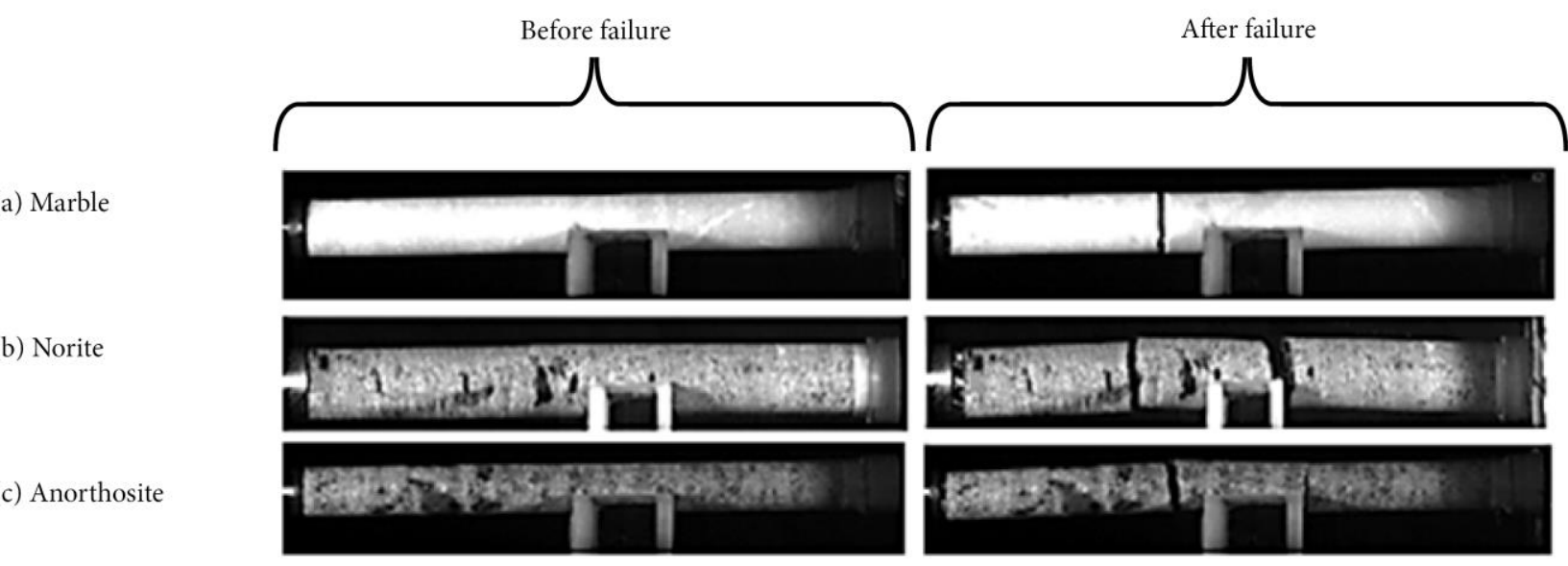

Figure 4 Different rock test specimens supported with $10 \mathrm{~mm}$ clay liner

\subsubsection{Tests with $30 \mathrm{~mm}$ thick concrete/clay liner combination (concrete/clay series)}

A combination of concrete and clay was attempted in order to assess their effectiveness in preventing dynamic rock failure. This composite of concrete/clay liner was made up of a $20 \mathrm{~mm}$ thick concrete liner, and a $10 \mathrm{~mm}$ thick clay liner. All the rock test specimens in Figure 5 show a three-spall fragmentation pattern. 
(a) Marble

Before failure

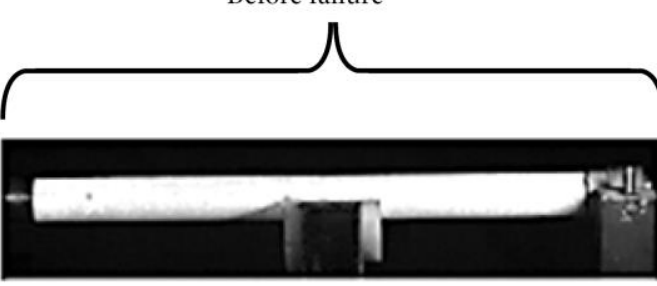

(b) Norite

(c) Anorthosite
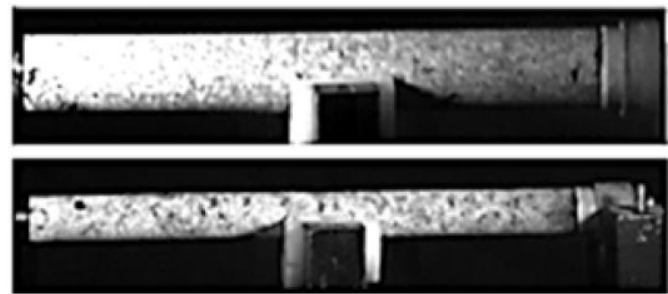

After failure
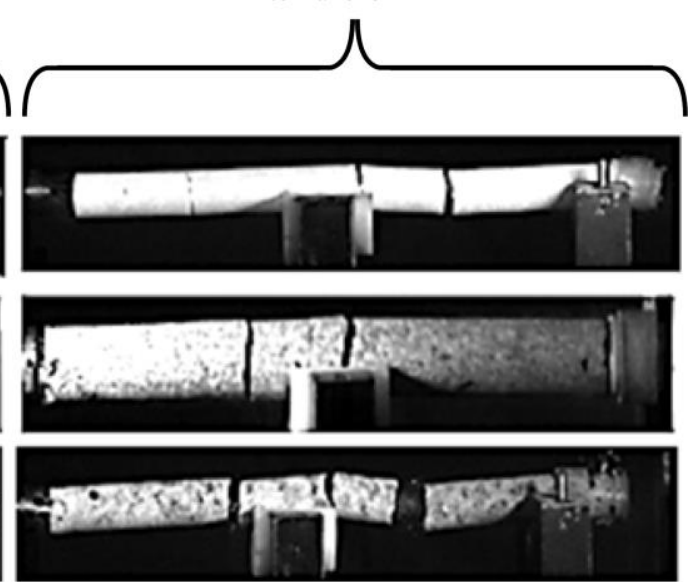

Figure 5 Different rock test specimens supported with $30 \mathrm{~mm}$ concrete/clay liner

\section{$4 \quad$ Further analysis and discussion of experimental results}

This section provides some useful insights into the effect of varying liner thickness on dynamic rock failure. In addition, the effect of impedance mismatch in layered systems and its influence to rock damage is also assessed.

\subsection{Effect of liner thickness on dynamic rock failure}

In order to study the effect of varying liner thickness $(\delta)$, it was decided to test respective liners with a constant thickness as an initial step toward examining their effectiveness to resist dynamic rock failure as reported in the previous section. Three series of liners, namely concrete, clay and concrete/clay combination are discussed.

\subsubsection{Concrete liner series}

Figure 6 depicts the behaviour of different rock types together with concrete as the concrete liner thickness is varied. The initial thickness of concrete liner used was about $45 \mathrm{~mm}$, which was then varied to $70 \mathrm{~mm}$ and $140 \mathrm{~mm}$. Frames 1, 2 and 3 numbered in ascending order for all rock types in Figure 6 (on the right hand side), indicate the decrease in rock fragmentation as the concrete liner thickness increases. Concrete liner thickness variation generally showed better performance in reducing spall damage, independent of rock type tested. Marble test specimens, with maximum thickness ( $140 \mathrm{~mm}$ ) of concrete liner, eliminated dynamic rock damage from occurring and this is a good example of how a sacrificial support ought to behave under dynamic loading. 


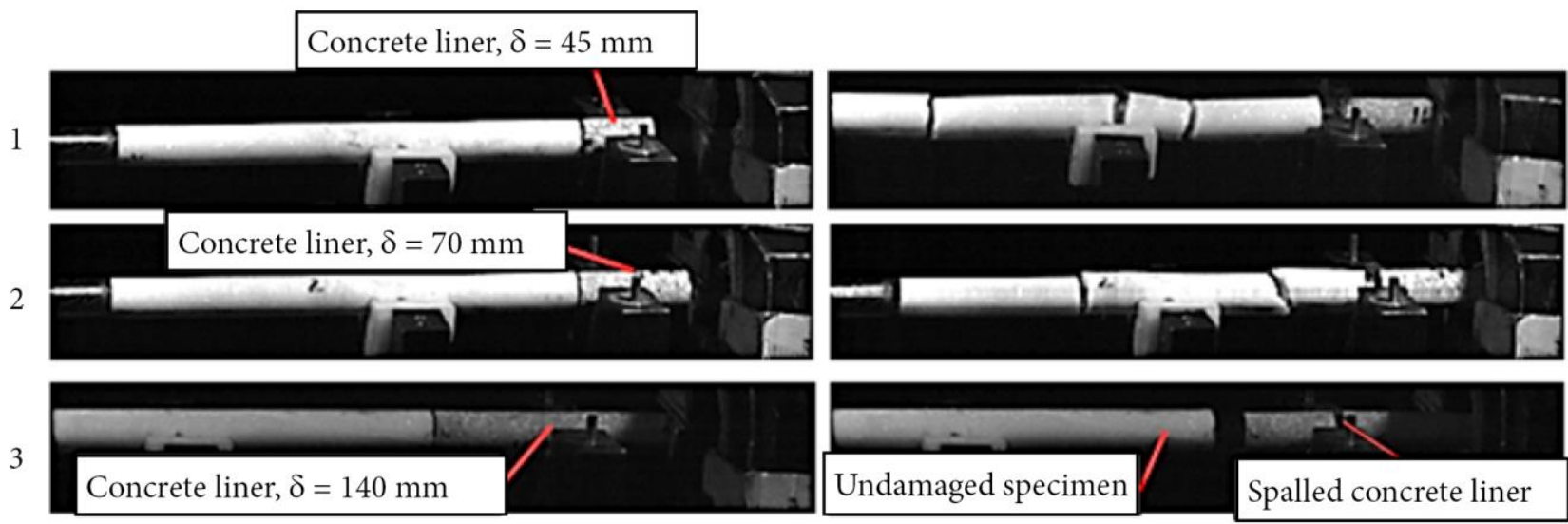

(a) Marble

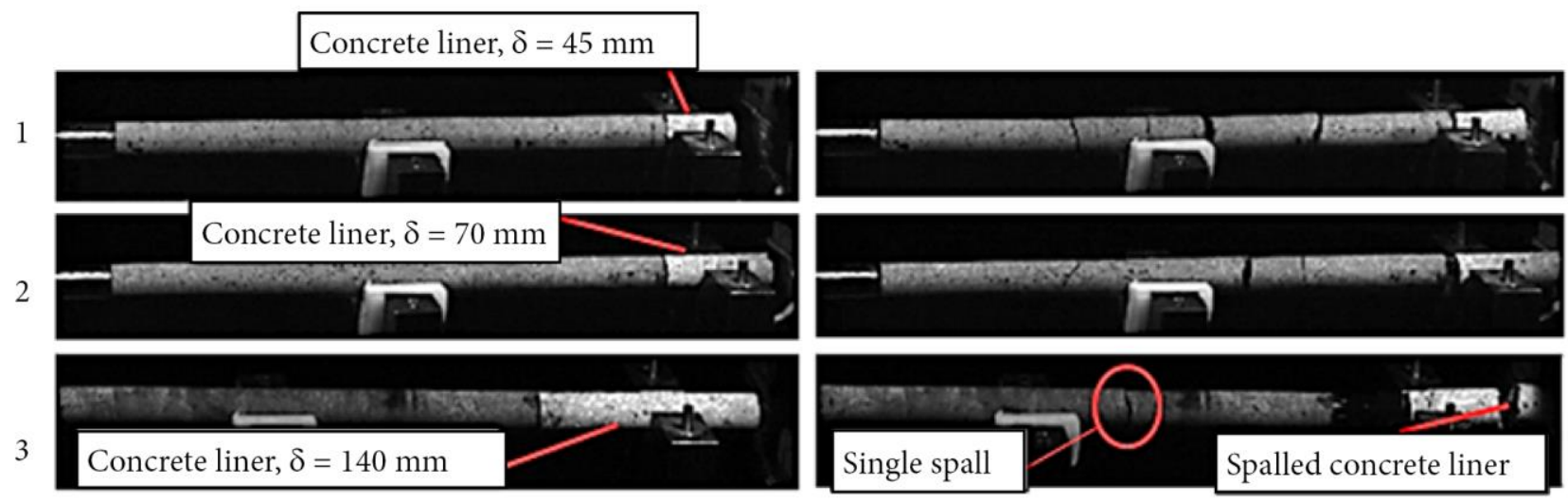

(b) Norite

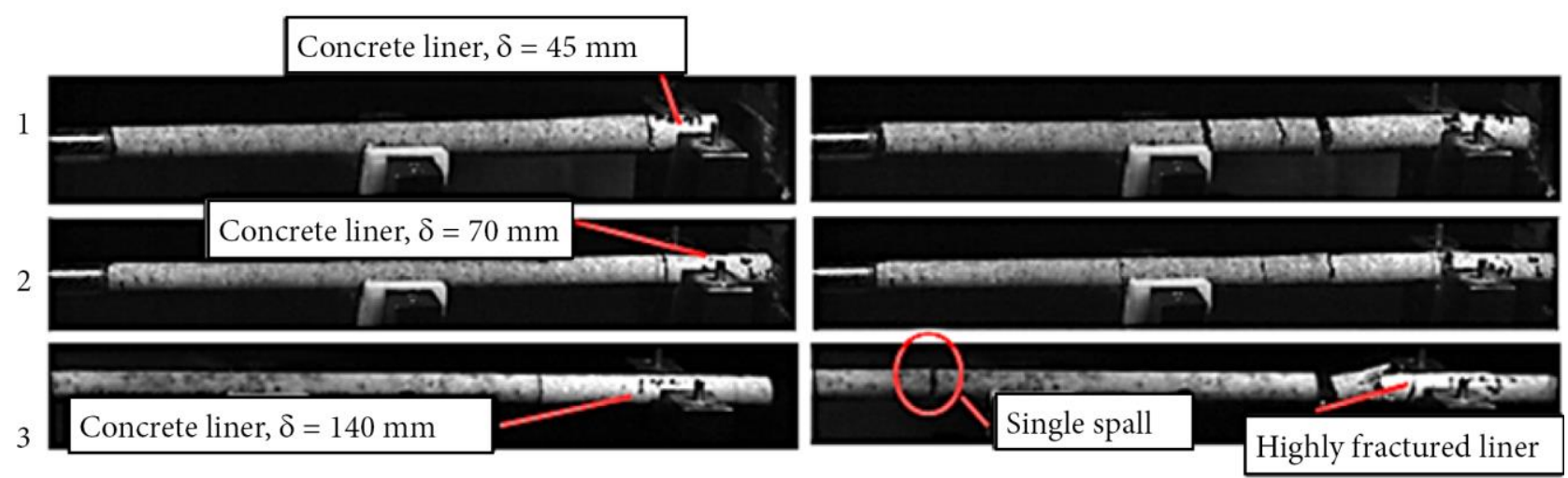

(c) Anorthosite

Figure 6 Dynamic behaviour of different rock types as the concrete liner thickness is varied

\subsubsection{Concrete/clay combination series}

In this series, the thickness of concrete liner was varied while the thickness of the clay liner was kept constant at $10 \mathrm{~mm}$ throughout testing. Different thicknesses considered for concrete liner can be seen in Figure 7. 


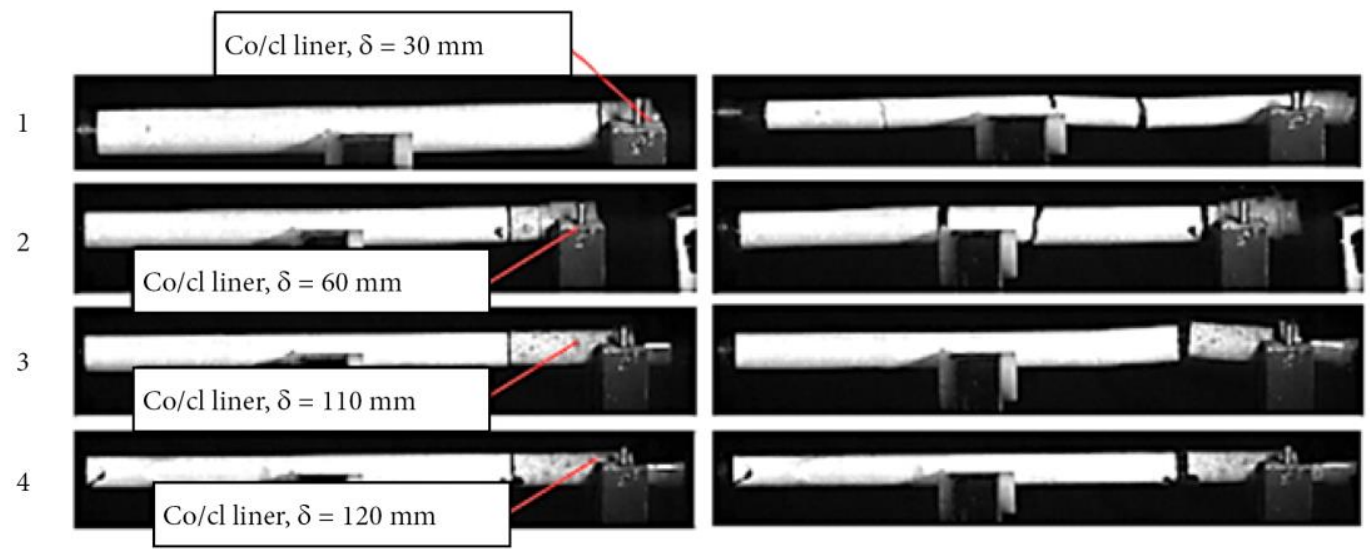

(a) Marble
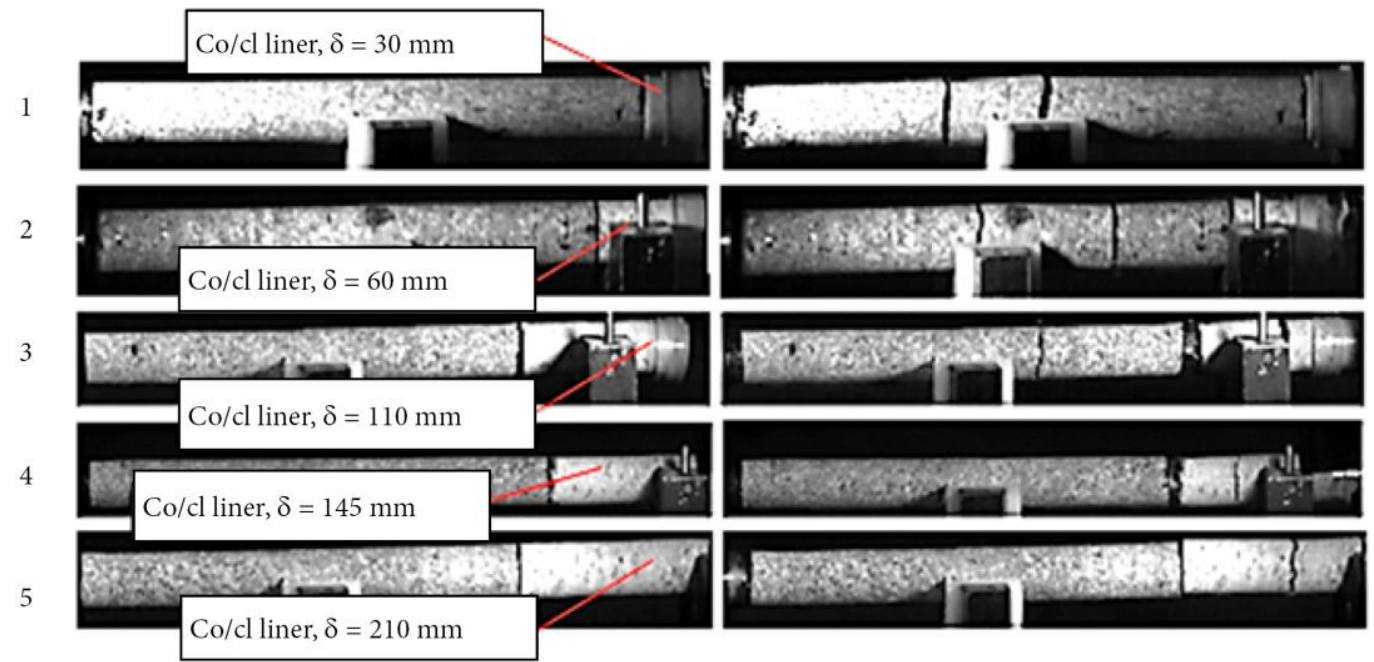

(b) Norite
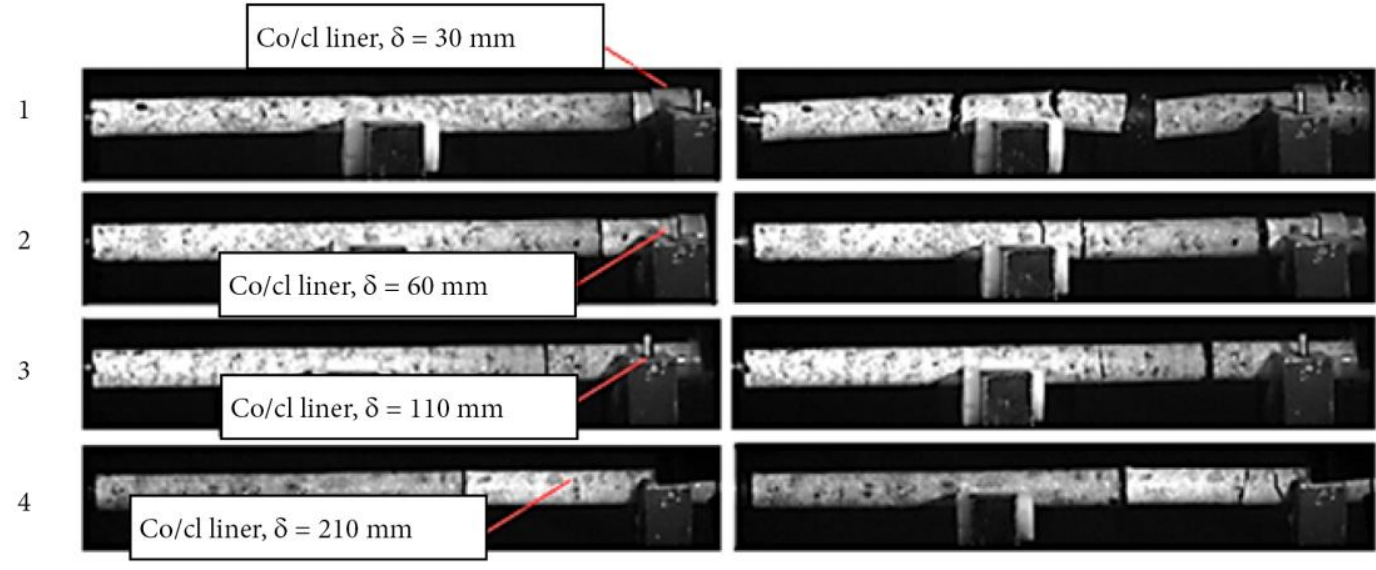

(c) Anorthosite

Figure 7 Dynamic behaviour of different rock types as the concrete/clay combination liner thickness is varied

For marble test specimens, failure was inhibited when the thickness of the liner was 110 and $120 \mathrm{~mm}$. This indicates that the clay liner could have absorbed the stress wave at concrete/clay liner interface, resulting in a decrease in strength of reflected tensile wave at the contact, reducing the potential to re-enter rock specimen again and cause rock damage due to stress wave superposition. Spall damage was prevented from occurring in both anorthosite and norite when the liner thickness was $200 \mathrm{~mm}$ long, and there are 
two possible reasons for such behaviour. Firstly, the duration of transmitted stress wave in concrete could have been prolonged, decreasing the chances of cyclic loading to rock specimen resulting from reflected tensile stress wave, which in turn may cause rock spall damage. In addition, spalling of liner support, as observed in cases of longer liners, might have helped in reducing the strength of the reflected tensile wave from concrete/clay liner contact through energy loss during the fracturing process. Secondly, damage was not apparent in either rock type due to the presence of the clay liner.

\subsubsection{Clay liner series}

This series shows opposite behaviour in terms of its ability to help combat dynamic rock fracturing. The behaviour of marble specimens is erratic considering that increasing a liner thickness impacts positively in reducing the degree of rock damage as learned previously. In this case, however, the number of fragments increased as the liner thickness increased, as shown in Figure 8. In brief, all of the test specimens failed despite an increase in liner thickness. This raises a fundamental question regarding the effectiveness of using 'soft' liner materials as support, and this is further investigated in the following section.

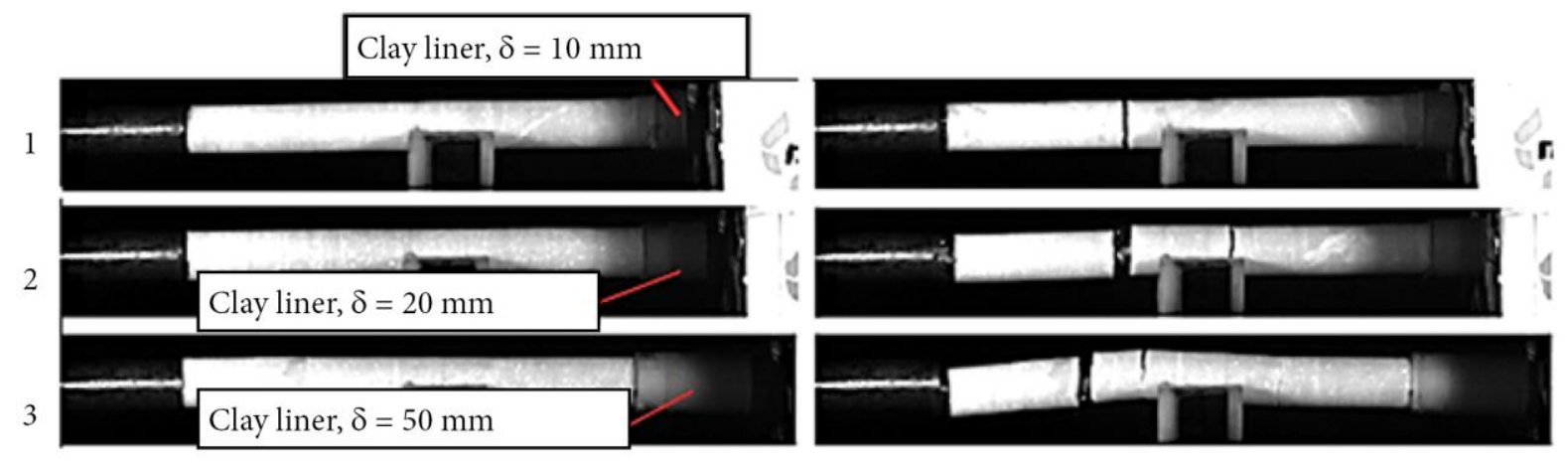

(a) Marble

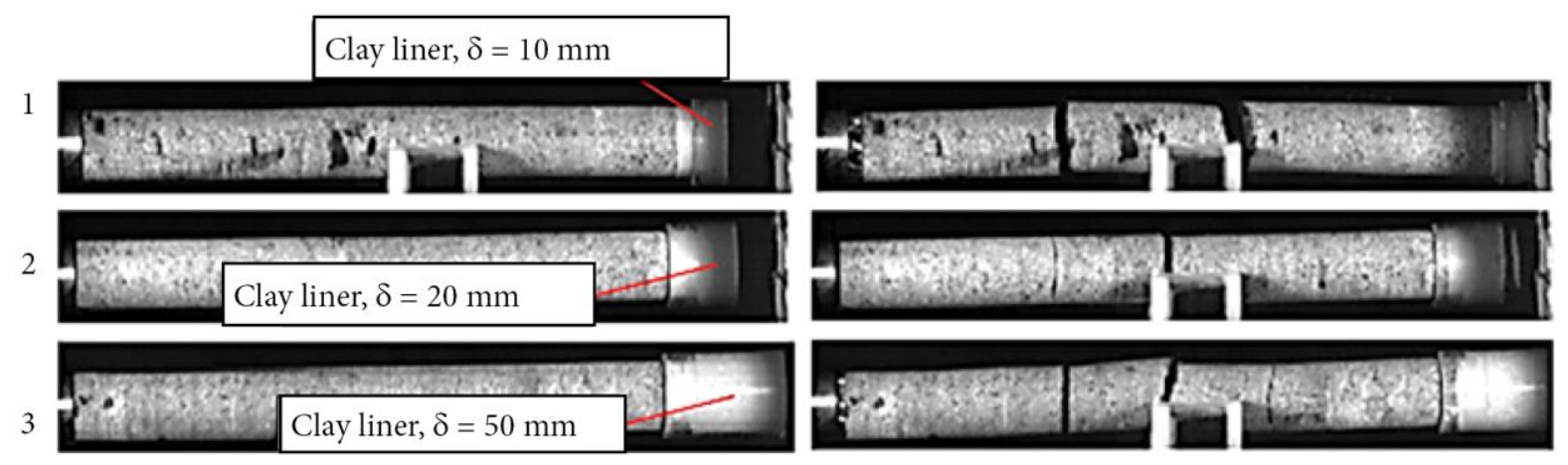

(b) Norite

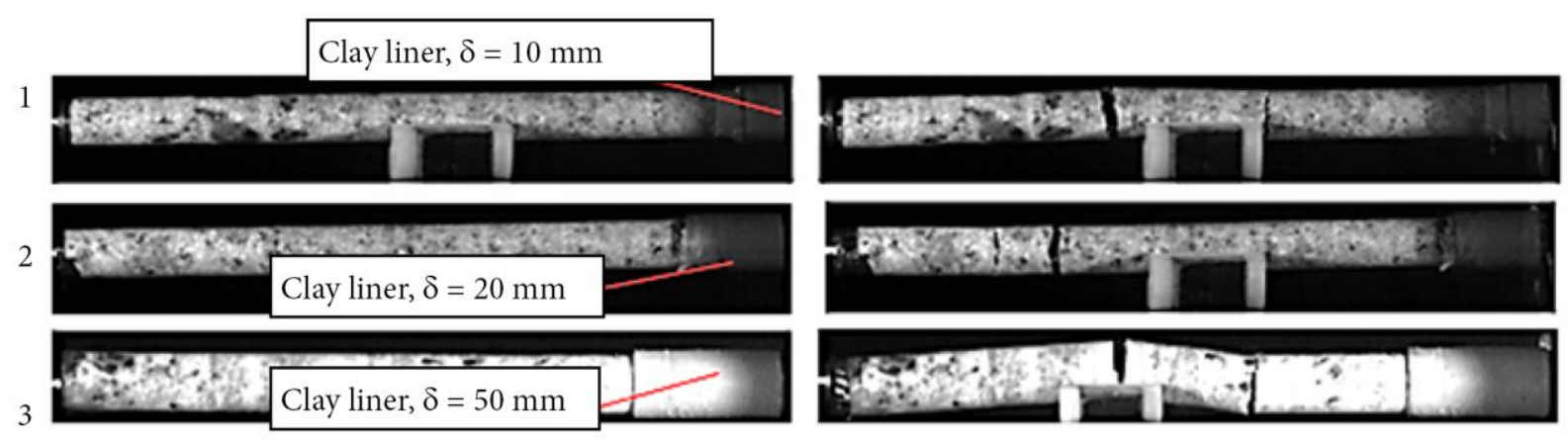

(c) Anorthosite

Figure 8 Dynamic behaviour of different rock types as the clay liner thickness is varied 


\subsection{Effect of mechanical impedance on rock damage in layered systems}

It was not practical to cement strain gauges on both the rocks and support liners, which were tested, in order to mirror the propagation of stress wave in the whole SHPB set-up. Instead, a basic analytical approach was used to determine the coefficients of transmission and reflection respectively using the following Equations:

$$
\begin{gathered}
\frac{\sigma_{\text {trans }}}{\sigma_{\text {inc }}}=\frac{2 \rho_{2} C_{2}}{\rho_{1} C_{1}+\rho_{2} C_{2}} \\
\frac{\sigma_{\text {refl }}}{\sigma_{\text {inc }}}=\frac{\rho_{2} C_{2}-\rho_{1} C_{1}}{\rho_{1} C_{1}+\rho_{2} C_{2}}
\end{gathered}
$$

The subscripts 1 and 2 denote HPB and rock specimen respectively. In cases when there are more than two liners, as in this study, Equation 1 can be applied consecutively to determine the transmission ratio into the third layer.

$$
\frac{\sigma_{\text {trans }}}{\sigma_{\text {inc }}}=\left[\frac{2 \rho_{2} C_{2}}{\rho_{1} C_{1}+\rho_{2} C_{2}}\right]\left[\frac{2 \rho_{3} C_{3}}{\rho_{2} C_{2}+\rho_{3} C_{3}}\right]
$$

Subscripts 3 in this regard represent a support liner. The transmitted stress wave in the second layer can be used as an incident stress to the third layer from Equation 3.

Tedesco and Landis (1989) reasoned that if the transmission and reflection of a stress wave in layered media is the function of impedance mismatch, then mechanical impedance could be manipulated to prevent internal damage of a layered structure subjected to external blast loads. Such an approach by the authors could as well yield positive outcomes in trying to prevent rock damage to an excavation supported with a liner under dynamic loading. Generally, all the 'layers' constituting the HPB in this study had different mechanical impedance, which can mathematically be expressed as: $\rho_{1} C_{1}>\rho_{2} C_{2}>\rho_{3} C_{3}$. The HPB was dynamically loaded in the stress region between $80 \mathrm{MPa}$ and $100 \mathrm{MPa}$. The percentage of transmitted stress wave in the first two media (i.e. Hopkinson bar and rock) without the liner (i.e. support liner) was sufficient to cause spall damage to rock upon reflection from the specimen free end. At least $45 \%$ of the stress wave was transmitted to the rock test specimen for all rock types, while about $55 \%$ was reflected back to the steel bar. About $80 \mathrm{MPa}$ was assumed as the input stress wave in the steel bar.

One of the liners that showed better performance in reducing or inhibiting rock damage is concrete. When the transmitted stress wave in the second layer is taken as an incident stress wave to the third layer from Equation 3, it was found that at least $80 \%$ of the stress wave was transmitted into the concrete for all rock types. To put this into perspective, the concrete used had high transmission ratios thereby preventing rock damage, since the reflected tensile wave was not strong enough to initiate rock damage, particularly in the case of marble test specimens with the maximum concrete liner. It has been observed that having 'perfect' impedance mismatch alone is not sufficient to guarantee prevention of dynamic rock failure. When a minimal thickness of concrete liner is used, it only traps the momentum transferred from the excited rock without necessarily altering the strength of stress wave at the contact. On the other hand, relatively long specimens permit the passage of the stress wave through the liner, and damage the liner upon reflection of the stress wave from the free end. It is postulated that, if the thickness of the concrete liner was further varied to $200 \mathrm{~mm}$ for the anorthosite and norite test specimens, failure could have been totally eliminated.

In the case of the concrete/clay liner combination, test specimens of all rock types were prevented from damage when a certain threshold of composite liner thickness was reached. The behaviour of the rock was primarily influenced by mechanical impedance of concrete as previously described, and by the clay liner as a secondary effect.

If less dense material is used as a liner to provide rock support, the greater will be the coefficient of reflection of the stress wave, resulting in significant rock damage. The behaviour of rock subjected to dynamic loading reported for the clay liner series is attributed to the low acoustic impedance of the clay material. 


\section{$5 \quad$ Concluding remarks}

This paper demonstrated, through controlled laboratory experiments, the potential benefits of using a sacrificial layer to help combat the effects of rockbursts caused by seismically induced shock/seismic waves. The importance of varying support liner thickness and using liners with different mechanical stiffness was investigated. The findings from experimental results in terms of behaviour and performance of sacrificial support are in agreement with the observations made by Stacey and Rojas (2013) in real rockburst events in a mine. It can be concluded, however, that having a liner material in place with the appropriate impedance relative to the rock is not sufficient to prevent rockburst damage without considering the effect of varying liner thicknesses. At present it is not possible to provide definite answers regarding the relationship between a liner's thickness and the mechanical impedance. The use of low impedance liner material relative to rock is not ideal in attempting to help combat rock damage, as briefly highlighted in the paper.

Future work is aimed at developing design guidelines for sacrificial support. A quantitative relationship between liner thickness, mechanical impedance of both rock and liner, and loading parameters must be established analytically. Verification of this relationship would entail a broader experimental programme involving different liner materials, supported by numerical simulations. Once design guidelines are established, field observations can then follow in real, seismically-active mining environments.

\section{Acknowledgement}

Some of the research on which this paper is based was supported in part by the National Research Foundation (NRF) of South Africa (Grant specific unique reference number (UID) 85971).

\section{Disclaimer}

The Grantholder (second author) acknowledges that opinions, findings and conclusions or recommendations expressed in any publication generated by the NRF supported research are that of the author, and that the NRF accepts no liability whatsoever in this regard.

\section{References}

Gamma, BA, Lopatnikov, SL \& Gillepsie, JW 2004, 'Hopkinson bar experimental technique: a critical review', Applied Mechanics Reviews, vol. 57, pp. 223-250.

Govender, RA, Louca, LA, Pullen, A, Fallah, AS \& Nurick, GN 2011, 'Determining the thorough-thickness properties of thick glass fiber reinforced polymers at high strain rates', Journal of Composite Materials, vol. 46, pp. 1219-1228.

Ortlepp, WD \& Stacey, TR 1997, 'Testing of tunnel support: dynamic load testing of rock support containment systems', Safety in Mines Research Advisory Committee, SIMRAC GAP Project 221.

Player, JR, Thompson, AG \& Villaescusa, E 2008, 'Dynamic testing of reinforcement systems', in TR Stacey \& DF Malan (eds), Proceedings of the Sixth International Symposium on Ground Support in Mining and Civil Engineering Construction, South African Institute of Mining and Metallurgy Symposium Series S51, Cape Town, pp. 581-595.

Stacey, TR \& Rojas, E 2013, 'A potential method of containing rockburst damage and enhancing safety using a sacrificial layer', Journal of the Southern African Institute of Mining and Metallurgy, vol. 113, pp. 565-573.

Stacey, TR 2012, 'A philosophical view on the testing of rock support for rockburst conditions', Journal of the Southern African Institute of Mining and Metallurgy, vol. 113, pp. 227-245.

Stacey, TR 1991, Method of and means for inhibiting rockbursts, Patent Application, Provisional Specification, registered through Adams and Adams, Patent Attorneys, Pretoria.

Tedesco, JW \& Landis, DW 1989, 'Wave propagation through layered systems', Computers and Structures, vol. 48, pp. 625-638.

Zhou, YX, Xia, K, Li, XB, Li, HB, Ma, GW, Zhao, J, Zhou, F \& Dai, F 2012, 'Suggested methods for determining the dynamic strength parameters and mode-I fracture toughness of rock materials', International Journal of Rock Mechanics and Mining Sciences, vol. 49, pp. 105-112. 